\title{
IMPROVING UNDERWATER ACCURACY BY EMPIRICAL WEIGHTING OF IMAGE OBSERVATIONS
}

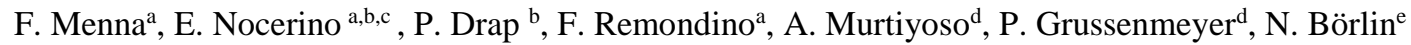 \\ a 3D Optical Metrology (3DOM) unit, Bruno Kessler Foundation (FBK), Trento, Italy - (fmenna, nocerino, remondino)@ fbk.eu \\ ${ }^{\mathrm{b}}$ LSIS, I\&M Team, Aix-Marseille Universite, Polytech Luminy, Marseille, France - (erica.nocerino, pierre.drap)@univ-amu.fr \\ c Theoretical Physics, ETH Zürich, Zurich, Switzerland - erican@ phys.ethz.ch \\ ${ }^{\mathrm{d}}$ Photogrammetry and Geomatics Group, ICube Laboratory UMR 7357, INSA Strasbourg, France - (arnadi.murtiyoso, \\ pierre.grussenmeyer)@insa-strasbourg.fr \\ e Department of Computing Science, Umeå University, Sweden - niclas.borlin@cs.umu.se
}

Commission II, WG 9

KEY WORDS: underwater photogrammetry, image quality, bundle adjustment, image observation weighting

\begin{abstract}
:
An underwater imaging system with camera and lens behind a flat port does not behave as a standard pinhole camera with additional parameters. Indeed, whenever the entrance pupil of the lens is not in contact with the flat port, the standard photogrammetric model is not suited anymore and an extended mathematical model that considers the different media would be required. Therefore, when dealing with flat ports, the use of the classic photogrammetric formulation represents a simplification of the image formation phenomenon, clearly causing a degradation in accuracy. Furthermore, flat ports significantly change the characteristics of the enclosed imaging device and negatively affect the image quality, introducing heavy curvilinear distortions and optical aberrations. With the aim of mitigating the effect of systematic errors introduced by a combination of (i) image quality degradation, induced by the flat ports, and (ii) a non-rigorous modelling of refraction, this paper presents a stochastic model for image observations that penalises those that are more affected by aberrations and departure from the pinhole model. Experiments were carried out at sea and in pools showing that the use of the proposed stochastic model is beneficial for the final accuracy with improvements up to $50 \%$.
\end{abstract}

\section{INTRODUCTION}

\subsection{Image quality degradation in water}

The use of a camera underwater differs significantly from its terrestrial use due to the medium where the images are acquired, which heavily influences the optical phenomena involved. Indeed, the presence of the water together with the type of pressure housing enclosing the camera act as additional optical elements. Because of the refractive effects of water, images taken underwater typically undergo (i) a substantial change in the geometry of image formation (change in the projection model, field of view, focussing) and (ii) a general image quality degradation.

Possible solutions to overcome or mitigate these issues consist in the use of optical elements that try to neutralise the effect of water through for example a spherical dome port or via an additional group of lenses like the Ivanoff-Rebikoff corrector (Ivanoff and
Cherney 1960, Rebikoff, 1968). Although more difficult to manufacture, these systems keep the main geometric characteristics of the lens unchanged when properly aligned to the camera lens (Slater, 2014; Menna et al., 2016) and allow the use of the standard photogrammetric mathematical model consisting of a pinhole camera with additional parameters (radial, decentring distortions, affinity and shear).

On the contrary, flat ports are the most common type of ports mounted on underwater pressure housings, being the less expensive to manufacture. Unfortunately, they significantly change the characteristics of the enclosed imaging device and negatively affect the image quality, due to curvilinear distortions and optical aberrations (e.g. lateral and axial chromatic aberrations and astigmatism).

A typical degradation behaviour is increasingly observed going from the image centre to the corners (Figure 1).

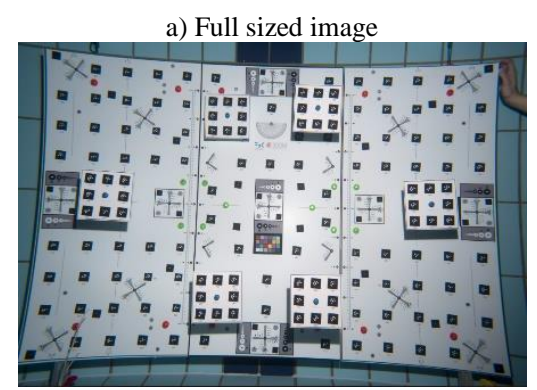

b) Upper left corner - crop

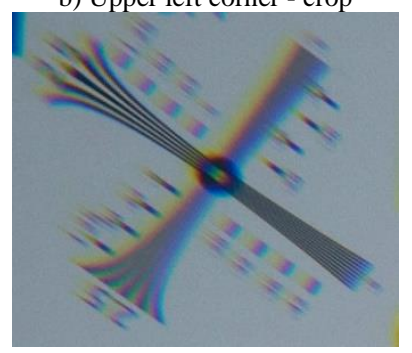

c) $2 / 3$ of $\max r$ - crop

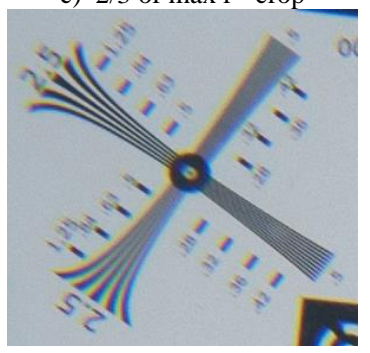

d) Centre - crop

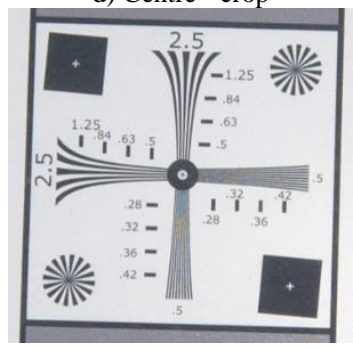

Figure 1. An image of the rectangular calibration object as described in (Menna et al., 2017) showing curvilinear pincushion distortion (a) Crops of the resolution patches respectively at upper left corner (b), 2/3 of max $\mathrm{r}(\mathrm{c})$ and at centre (d). 


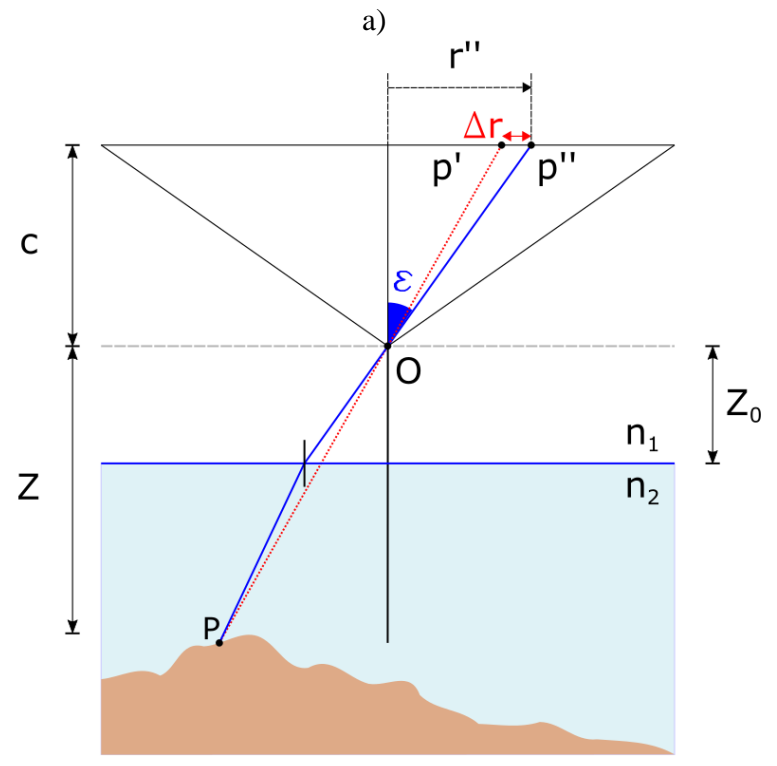

b)

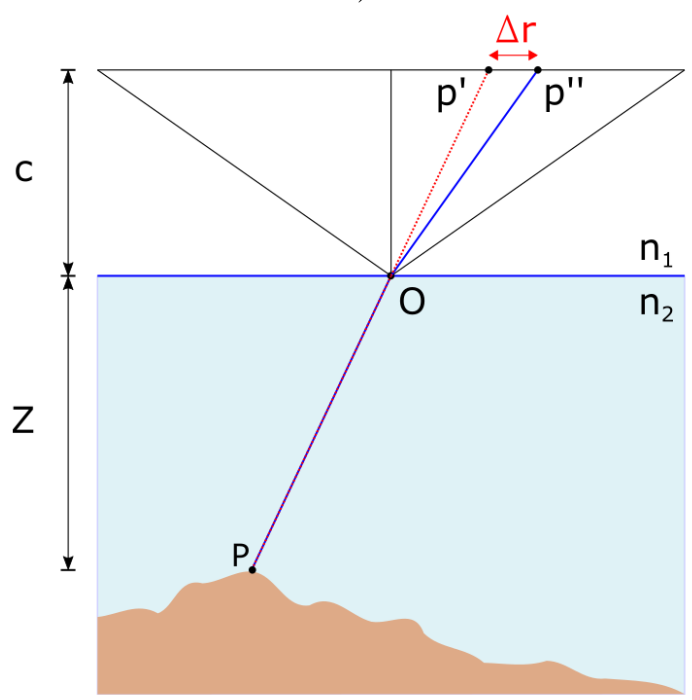

Figure 2. Schematic representation of a pinhole camera observing a submersed scene trough a flat separation surface. The 2 figures differ for the position of the centre of perspective (entrance pupil, $\boldsymbol{O}$ ) located respectively above (a) and on (b) the separation surface (up).

\subsection{Rigorousness vs simplicity}

An underwater imaging system with camera and lens behind a flat port does not behave as a standard camera in out-of-water conditions (pinhole with additional parameters such as radial, decentring distortions, affinity and shear factors). Indeed, whenever the entrance pupil of the lens is not in contact with the flat port, the standard photogrammetric model is not suited anymore and an extended mathematical model that takes into account the different media would be required.

With the aim to properly model the optical paths of rays, different geometrical interpretations have been proposed by different authors who have explicitly modelled the additional distortion effects caused by refraction (Maas, 1992, 2015), traced the optical path through the various interfaces (Kotowski, 1988, Li et al., 1997; Telem and Filin, 2010) or by introducing a nonsingle view point interpretation (Jordt-Sedlazeck and Koch, 2012).

These specialised models rigorously take into consideration the major sources of errors when dealing with multimedia interfaces; unfortunately, these are not commonly implemented in commercial software and thus not available to most users.

A direct effect, when dealing with flat ports, is that the use of standard photogrammetric model (Brown, 1971) represents a simplification of the image formation phenomenon, clearly causing a degradation in accuracy.

\subsection{Image formation with flat port pressure housing}

Figure 2 shows a simplified schema of a pinhole camera behind a flat port that observes a point $\boldsymbol{P}$ placed underwater. The figure is drawn by applying Snell's law. In an ideal situation, the object point $\boldsymbol{P}$, centre of perspective $\boldsymbol{O}$ (entrance pupil) and image projection $\boldsymbol{p}$ ' can be linked together by a collinearity straight line depicted in red. A radial component correction $\Delta r$ must be known (i.e. from a self- calibration) for this aim.

According to the model described in Kotowski (1988) and Luhmann et al. (2013), this radial component depends on the distance $\boldsymbol{Z}_{\boldsymbol{\theta}}$ between the entrance pupil $\boldsymbol{O}$ and the flat port, the angle $\boldsymbol{\varepsilon}$ of incidence of the incoming ray and the distance $\boldsymbol{Z}$ of the object point. With this geometrical interpretation, varying the position of the object point $\boldsymbol{P}$ along the blue ray underwater will cause the red straight line to vary in inclination and thus a different $\Delta \boldsymbol{r}$ will be necessary. When $\boldsymbol{Z}_{\boldsymbol{\theta}}$ approaches zero, i.e. the entrance pupil $\boldsymbol{O}$ lies on the flat port, a unique radial distortion is necessary for all the points lying on the $\boldsymbol{O P}$ segment. In this case, it can be demonstrated through numerical simulations that the Brown formulation (Brown, 1971) can be used without introducing systematic errors of any practical consequences.

In common systems with flat ports for underwater photography, the entrance pupil $\boldsymbol{O}$ is never on the glass of the flat port. This introduces systematic errors whose entity, for a given distance $\boldsymbol{Z}$, increases for points imaged towards the corner of the image format and is null for points imaged at the centre where refraction, according to the Snell's law, is zero.

Therefore, depending on the accuracy requirements of a given project, Brown model could be still accepted, given its simplicity and availability in both commercial and research software. On the other hand, when accuracy and rigorousness matter, a correct handling of this issue is mandatory.

\subsection{Aim of the paper}

In previous studies (Menna et al., 2017; Menna et al., 2018), the authors started an investigation on the accuracy degradation due to the worsening of image quality underwater, arising from both the pressure housing and port used, and the physical and environmental properties of water itself.

Comparative analyses were carried out using the same camera and lens in a waterproof housing equipped with both dome and flat ports. Two tests were performed: (i) system self-calibration and image quality evaluation using a specifically designed underwater test object (Figure 1 and Figure 3a); (ii) 3D modelling of a semi submerged industrial structure of about $20 \times 10 \mathrm{~m}^{2}$ (Figure 3b). Calibrations on the test object showed a degradation of accuracy when using the flat port with respect to the dome port, featuring high RMS of image residuals, a less precise calibration (worse standard deviations for camera parameters), and a lower 3D point precision in object space.

Starting from the findings anticipated in the previous studies, this paper further explores the possibility of improving the accuracy in underwater photogrammetry when using flat ports.

With the aim of mitigating the effect of systematic errors introduced by a combination of (i) image quality degradation, induced by the type of ports, and (ii) the departure from the pinhole camera plus Brown (1971) distortion model caused by a 


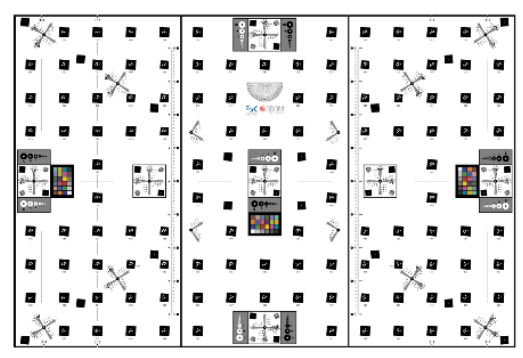

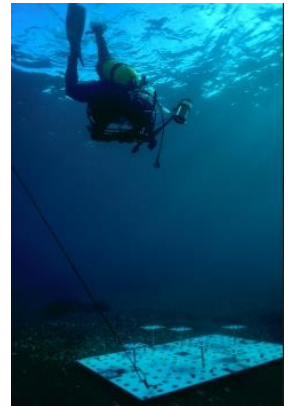

Figure 3. The modular test object used to study the effect of different weighting of the image observations together with a picture of a diver during the image acquisition stage (a). The semi-submerged industrial structure located in the Bay of Rogiolo near Livorno, Italy (Menna et al., 2018) with superimposed in red the circular loop strip along which underwater photographs were acquired (b). non-rigorous modelling of refraction, this paper presents a stochastic model for image observations that penalises those that are more affected by aberrations and departure from the pinhole model.

The assumption that a homogenous measurement accuracy can be assigned to image observations in both $\mathrm{x}$ and $\mathrm{y}$ image directions and across the whole image format, as it is a common practice in above-water photogrammetry, cannot hold anymore in many underwater scenarios. Therefore, a homogeneous weighting of image observations may not be the right choice. Instead, a varying image weighting might provide a better interpretation of the stochastic model, closer to the physical phenomena involved in the image formation in water.

To demonstrate that the use of a different weighting is beneficial for the final accuracy, different datasets are analysed where the bundle adjustment is run with homogeneous weighting of image observations and with a radial penalty (the more inclined the ray the less the weight for the corresponding image observation).

For our tests, the open source damped bundle adjustment toolbox DBAT (Börlin and Grussenmeyer, 2013 ${ }^{1}$ ) v0.7.2.0 for MATLAB environment is used. a)
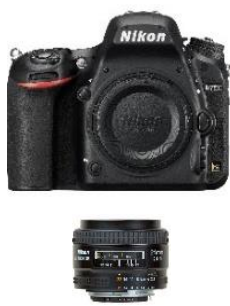

c)

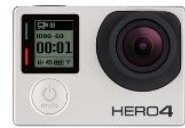

b)

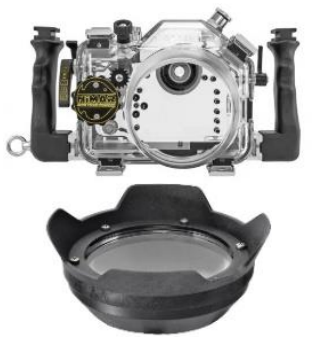

d)

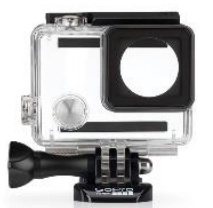

Figure 4. Camera systems and waterproof housing used for the experiments. The Nikon D750 DSLR camera (a) with NiMAR NI3D750ZM pressure housing (b). The GoPro HERO4 Black (c) in its dedicated waterproof housing $(\mathrm{d})$.

${ }^{1}$ https://github.com/niclasborlin/dbat

\section{UNDERWATER IMAGING SYSTEMS}

The image datasets used for this study were collected using two different systems (Figure 4):

i) Nikon D750 $24 \mathrm{Mpx}$ full frame DSLR mounting a Nikkor $24 \mathrm{~mm} \mathrm{AF} \mathrm{f/2.8} \mathrm{D} \mathrm{enclosed} \mathrm{in} \mathrm{NiMAR} \mathrm{NI3D750ZM}$ pressure housing with a NiMAR flat port specifically built for the experiments reported in this manuscript.

ii) GoPro HERO4 Black fisheye lens action camera in its dedicated waterproof housing featuring a flat port

For system (i) the distance of the entrance pupil from the internal surface of the flat port was measured using another camera mounted on a linear stage to act as a collimator (Figure 5) according to the procedure described in Menna et al. (2016). The value $\boldsymbol{Z}_{\boldsymbol{\theta}}$ (Figure 2) was found to be about $50 \mathrm{~mm}$. For system (ii) the entrance pupil could not be collimated but a plausible value for $\boldsymbol{Z}_{\boldsymbol{\theta}}$ can be estimated to be about 4-5 mm maximum.

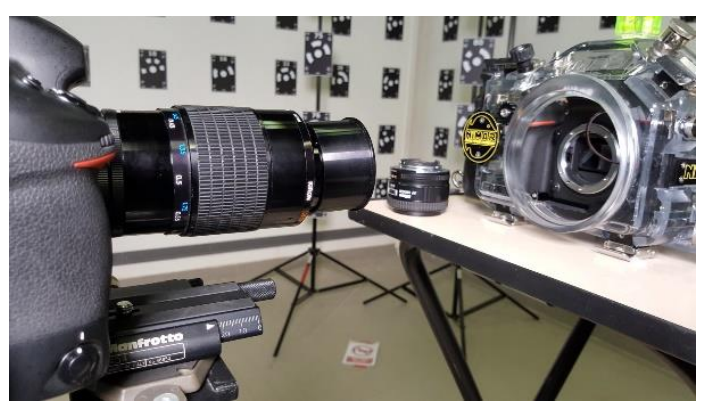

Figure 5. The Nikon D750 DSLR camera with NiMAR NI3D750ZM pressure housing during the measurement of $\boldsymbol{Z}_{\boldsymbol{\theta}}$ in laboratory.

\section{EXPERIMENTS}

\subsection{Employed image datasets}

Experiments were carried out both at sea and in swimming pools. Seven different image datasets were chosen for this study:

- 5 image networks of the modular test object (Fig. 3a) were performed with a flat port, 2 realized at sea and 2 in pools, thus providing different conditions in particular with respect to water transparency which was naturally worse at sea. The fifth dataset consisted in the calibration of the same Nikon camera with NiMAR housing but mounting a dome port. This 
system provided the most accurate results in different previous experiments carried out by the authors thus it is reported here for completeness. A typical camera network for self-calibration was used for all calibration datasets with multi-view convergent images and roll diversity (Fraser, 1997). In order to guarantee the highest accuracy, during calibrations, each image acquisition was carried out with fixed focus set for the first image of the sequence and left unchanged for the entire tests.

- 2 underwater networks of a submerged structure located in the Bay of Rogiolo near Livorno, Italy, today abandoned and under consideration for restoration (Menna et al, 2018). The dataset consists of a singular open loop strip taken at about 2.5 meters. $80 \%$ overlap was considered along the strip and some convergent and rolled images were acquired to improve the self-calibration (especially considering the geometric characteristics of the object that is flat within the field of view of the single images). One dataset was acquired with the flat, and one with the dome. As before, the results achieved with the dome port are reported for completeness.

Detailed information of each dataset is reported in Table 1 and 2. All the tests were performed in shallow water at a maximum depth of 5 meters.

\subsection{Methods for accuracy evaluation}

When it comes to underwater 3D metrology, accuracy potential is hard to validate against an independent external standard. The main reason is that logistics is much more complex under than above water and the use of well-known standard protocols for acceptance and verification (like the German VDI/VDE 2634, 2002) is seldom feasible. Good figures of the quality of underwater calibrations can be drawn by analysing the bundle adjustment results, such as the standard deviations of calibration parameters, RMS of image residuals and coordinate precision in object space, though this is not sufficient to assess the accuracy in object space. Therefore, it is common knowledge that an external independent check is required. In this study, reference distances of five different lengths (Figure 6) were used to evaluate the external accuracy of the calibration datasets.

The reference values were provided by a calibration made in the laboratory of 3DOM-FBK. Possible deformations of the panels are taken into account by analysing the deviations from least square fitted planes for each of the three panels forming the test object. Only those lengths whose potential errors are below 15 $\mu \mathrm{m}$ (chord against arc length) are considered for the accuracy assessment.

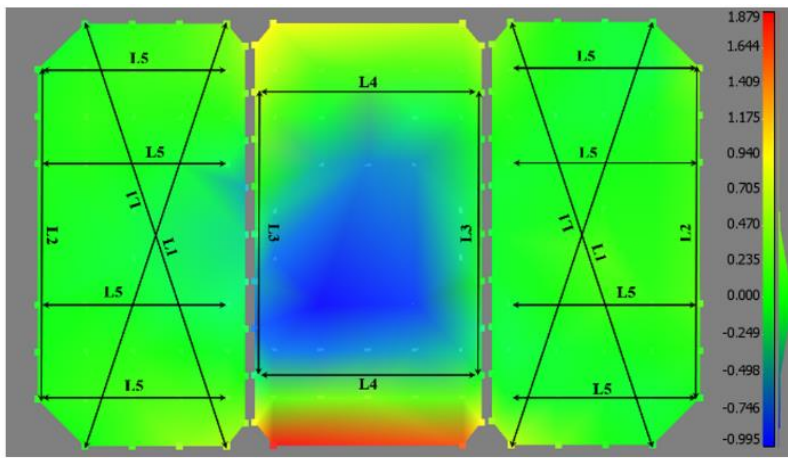

Figure 6. Reference distances used for the accuracy evaluation. Nominal values for the reference distances are $L 1=950 \mathrm{~mm}, \mathrm{~L} 2=700$, $\mathrm{L} 3=600, \mathrm{~L} 4=480, \mathrm{~L} 5=400$. The three panels of the test object are coloured according to their deformation from planar surfaces fitting the 3D points.
The length measurement error $(L M E)$ and relative length measurement accuracy (RLMA) are computed according to equation 1 and 2 respectively:

$$
\begin{gathered}
L M E=D_{m}-D_{r} \\
R L M A=1 \text { : round }\left(\left|\frac{D_{r}}{D_{m}-D_{r}}\right|\right)
\end{gathered}
$$

where $D_{m}$ and $D_{r}$ are the measured and reference distances.

The theoretical LME of the laboratory reference measurement for the modular test object at $99 \%$ confidence level is $0.078 \mathrm{~mm}$. For the dataset of the submerged structure located in the Bay of Rogiolo a reference distance was measured by tape at the main entrance of the rectangular basin. A value of $4.723 \mathrm{~m}$ was recorded with an estimated accuracy of about $1 \mathrm{~cm}$.

\section{EMPIRICAL WEIGHTING OF IMAGE OBSERVATIONS}

The preliminary processing was performed in PhotoModeler Scanner v. 2013 and PhotoScan v 1.2.6, respectively for the calibration and the semi-submerged structures. The image observations were then imported in DBAT, along with the interior and exterior orientation parameters and 3D tie points coordinates used as initial values for a minimally constrained self-calibrating BA. To fix the datum, i.e. the seven degrees of freedom (DOF) needed for solving the system of equations, the six exterior orientation parameters (three translations and three rotations) of the camera located nearest to the barycentre of the camera newtork was fixed. To solve the scale ambiguity, an averaging scale factor was computed on multiple bars of known lenght. Two different tests were run: as first instance, a homogeneous and constant weight of 0.1 pixels was provided to the image observations. The second processing entailed an empirical weighting function based on both experimental evidence and theoretical considerations. Analyses on image quality based on MTF measurements (Menna et al, 2017) showed that the centre of the image format is characterised by a resolution at least 4-5 times better than the corner. This can be easily confirmed by a visual inspection of Figure 1: the centre of the image (Figure 1d) appears of higher quality than the corners (Figure 1b). This finding is also confirmed by the theory: the error committed without a non-proper modelling of multimedia refraction is more significant towards the corners where incoming rays are more inclined than towards the centre. The implemented empirical weighting function varies in the range between 0.1-5 pixel, from the centre towards the borders. In other words, observations after $2 / 3$ of the image format are more significantly penalized (Figure 7).

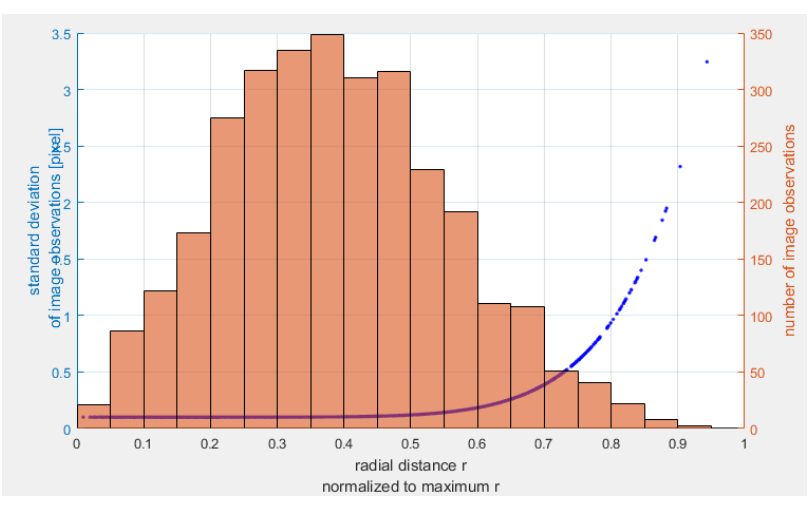

Figure 7. Histogram of image observations as function of normalised radial distance for the dataset \#1_Cal_FLAT Quercianella. The blue curve represents the empirical standard deviations employed to weight the image observations in the bundle adjustment. 


\begin{tabular}{|c|c|c|c|c|c|c|c|c|c|}
\hline & $\begin{array}{l}\text { ND750 DOME } \\
\text { PORT }\end{array}$ & \multicolumn{2}{|c|}{$\begin{array}{c}\text { ND750 } \\
\text { FLAT PORT }\end{array}$} & \multicolumn{2}{|c|}{$\begin{array}{c}\text { ND750 } \\
\text { FLAT PORT }\end{array}$} & \multicolumn{2}{|c|}{$\begin{array}{l}\text { GOPRO HERO4 } \\
\text { BLACK }\end{array}$} & \multicolumn{2}{|c|}{$\begin{array}{l}\text { GOPRO HERO4 } \\
\text { BLACK }\end{array}$} \\
\hline Dataset & $\begin{array}{c}\text { \#0_Cal_DOME } \\
\text { Quercianella }\end{array}$ & \multicolumn{2}{|c|}{$\begin{array}{c}\text { \#1_Cal_FLAT } \\
\text { Quercianella }\end{array}$} & \multicolumn{2}{|c|}{$\begin{array}{c}\text { \#2_Cal_FLAT } \\
\text { Rane Nere }\end{array}$} & \multicolumn{2}{|c|}{$\begin{array}{c}\text { \#3_Cal_GoPro } \\
\text { Quercianella }\end{array}$} & \multicolumn{2}{|c|}{$\begin{array}{c}\text { \#4_Cal_GoPro } \\
\text { Marseille }\end{array}$} \\
\hline Water type & sea & \multicolumn{2}{|c|}{ sea } & \multicolumn{2}{|c|}{ pool (chlorinated) } & \multicolumn{2}{|c|}{ sea } & \multicolumn{2}{|c|}{ pool (chlorinated) } \\
\hline Number of images & 25 & \multicolumn{2}{|c|}{34} & \multicolumn{2}{|c|}{34} & \multicolumn{2}{|c|}{35} & \multicolumn{2}{|c|}{202} \\
\hline $\begin{array}{c}\text { Average number } \\
\text { of rays per object } \\
\text { point }\end{array}$ & 13 & \multicolumn{2}{|c|}{16} & \multicolumn{2}{|c|}{25} & \multicolumn{2}{|c|}{21} & \multicolumn{2}{|c|}{25} \\
\hline $\begin{array}{c}\text { Number of image } \\
\text { points }\end{array}$ & 2584 & \multicolumn{2}{|c|}{3068} & \multicolumn{2}{|c|}{4071} & \multicolumn{2}{|c|}{3477} & \multicolumn{2}{|c|}{2000} \\
\hline GSD [mm] & $\approx 0.25$ & \multicolumn{2}{|c|}{$\approx 0.25$} & \multicolumn{2}{|c|}{$\approx 0.25$} & \multicolumn{2}{|c|}{$\approx 0.4$} & \multicolumn{2}{|c|}{$\approx 0.2$} \\
\hline Weight type & constant & constant & $\begin{array}{l}\text { radial } \\
\text { penalty }\end{array}$ & constant & $\begin{array}{l}\text { radial } \\
\text { penalty }\end{array}$ & constant & $\begin{array}{l}\text { radial } \\
\text { penalty }\end{array}$ & constant & $\begin{array}{l}\text { radial } \\
\text { penalty }\end{array}$ \\
\hline $\begin{array}{l}\text { RMS point } \\
\text { residuals [pixel] }\end{array}$ & 0.330 & 0.829 & 0.863 & 0.589 & 0.606 & 3.703 & 4.032 & 0.824 & 0.893 \\
\hline $\begin{array}{c}\text { RMS of LME } \\
{[\mathrm{mm}]}\end{array}$ & 0.082 & 0.212 & 0.164 & 0.197 & 0.149 & 0.653 & 0.552 & 0.417 & 0.268 \\
\hline $\begin{array}{c}\text { RLMA } \\
\text { WRT a maximum } \\
\text { dimension of } 1800 \\
\text { mm } \\
\end{array}$ & $\approx 1: 22000$ & $\approx 1: 8500$ & $\approx 1: 11000$ & $\approx 1: 9100$ & $\approx 1: 12000$ & $\approx 1: 2800$ & $\approx 1: 3300$ & $\approx 1: 4300$ & $\approx 1: 6700$ \\
\hline $\begin{array}{l}\text { Relative } \\
\text { improvement by } \\
\text { empirical } \\
\text { weighting }\end{array}$ & - & & & & & & & & \\
\hline
\end{tabular}

Table 1. Summary of length measurement error from the different bundle adjustment results on the calibration test object

\section{RESULTS}

\subsection{Underwater calibration datasets}

The results of calibration datasets are summarised in Tables 5 . The main statistics from the BA and the accuracy valuation on 18 known distances on the three panels of the test object (Figure 6) in terms of $L M E$ and $R L M A$ are reported.

Worst RMS point residuals, $L M E$ and $R L M A$ are generally observed for the calibration at sea than in the pool.

The adoption of the radial weigh results in an expected, increased image point RMS, accompanied with an improvement in the object space, testified by lower $L M E$ and higher RLMA values.

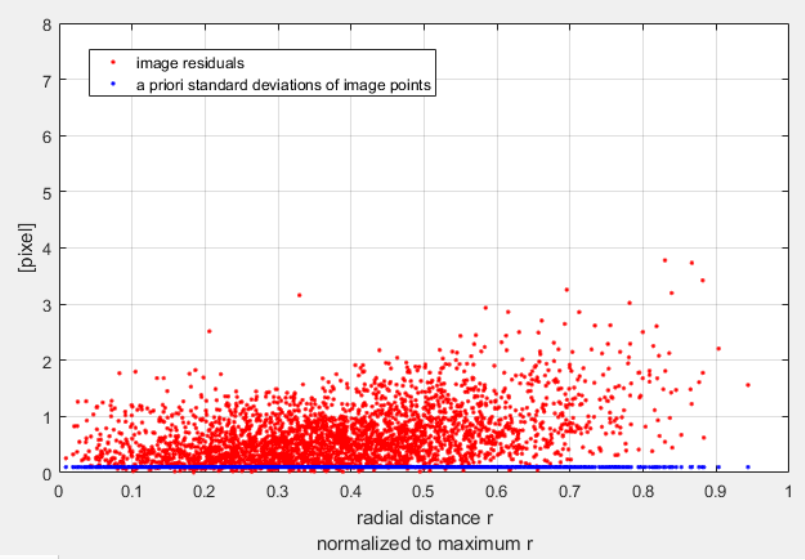

The achieved improvements are consistent for calibration results of the full-frame DSLR camera with flat port at sea and in the pool. On the contrary, the enhanced accuracy for the GoPro in the pool is doubled than at sea.

Figure 8 shows the absolute magnitude of image observation residuals as function of the normalised radial distance from the BA results for the dataset \#1_Cal_FLAT Quercianella. When a radial weight is applied the residuals decrease towards the centre of the image format and then follow the applied weighting function.

Figure 8. Absolute magnitude of image observation residuals (red) as function of the normalised radial distance from the BA results for the dataset \#1_Cal_FLAT Quercianella. The blue curves represents respectively the constant weight of 0.1 pixels provided to the image observations (left) and the empirical weighting function (right). 


\begin{tabular}{|c|c|c|c|}
\hline & $\begin{array}{l}\text { ND750 DOME } \\
\text { PORT }\end{array}$ & \multicolumn{2}{|c|}{$\begin{array}{c}\text { ND750 } \\
\text { FLAT PORT }\end{array}$} \\
\hline Dataset & $\begin{array}{c}\text { \#0_3D_MODELING } \\
\text { Quercianella }\end{array}$ & \multicolumn{2}{|c|}{$\begin{array}{c}\text { \#5_3D_MODELING } \\
\text { Quercianella }\end{array}$} \\
\hline Water type & sea & \multicolumn{2}{|c|}{ sea } \\
\hline $\begin{array}{c}\text { Number of } \\
\text { images }\end{array}$ & 265 & \multicolumn{2}{|c|}{205} \\
\hline $\begin{array}{c}\text { Average } \\
\text { number of } \\
\text { rays per } \\
\text { object point }\end{array}$ & 4 & \multicolumn{2}{|c|}{4} \\
\hline $\begin{array}{l}\text { Number of } \\
\text { image points }\end{array}$ & 377499 & \multicolumn{2}{|c|}{225171} \\
\hline GSD [mm] & $\approx 0.5$ & \multicolumn{2}{|c|}{$\approx 0.5$} \\
\hline Weight type & constant & constant & $\begin{array}{l}\text { radial } \\
\text { penalty }\end{array}$ \\
\hline $\begin{array}{l}\text { RMS point } \\
\text { residuals } \\
\text { [pixel] }\end{array}$ & 0.811 & 1.342 & 1.610 \\
\hline $\begin{array}{l}\text { Loop closure } \\
\text { error }[\mathrm{cm}]\end{array}$ & 2.3 & 8.8 & 4.4 \\
\hline $\begin{array}{c}\text { Relative } \\
\text { improvement } \\
\text { by empirical } \\
\text { weighting }\end{array}$ & - & \multicolumn{2}{|c|}{$50 \%$} \\
\hline
\end{tabular}

Table 2. Summary of the results for the dataset of the semisubmerged industrial structure located in the Bay of Rogiolo, near Livorno, Italy.

\subsection{Semi-submerged industrial structure dataset}

Table 2 reports the results of the open loop strip camera network for the semi-submerged structure. The findings from the calibration datasets are confirmed: when the empirical weighting function is applied, the image point RMS increases, but a significant improvement of about the $50 \%$ is obtained in the object space. The $L M E$ and $R L M A$ are computed with respect to the loop closure reference length $4.723 \mathrm{~m}$ at the entrance of the basin, measured by tape measurement.

\section{DISCUSSIONS AND FUTURE WORKS}

This study showed that despite a non-rigorous modelling of ray tracing as needed for flat ports, the results achieved may be sufficient for many applications even if the results are not as accurate as when using the more expensive dome ports (Tables 1 and 2).

The employed empirical weighting to consider image degradation towards the borders of the image due to physical optical phenomena provided promising results (improvement from 20-50\%). The systematic improvements support the thesis that image observations should be weighted according to their expected accuracy, a practice very common in the surveying discipline (Ghilani, 2017) where for example distance observations between two points are penalised according to their length (the longer the distance, the less weight is assigned).

The processing in DBAT allowed to factor the weight in the bundle adjustment in a very flexible way and to achieve significant accuracy improvements, particularly for the industrial structure dataset.

RMS point residuals at sea are significantly worse than in the pool mainly due to a combination of unfavourable environmental conditions such as water turbidity, swell and lighting.
Also, more complex weighting functions are under investigation, to take into account both the worsening of the optical quality towards the image borders and refraction effects by introducing a correction coefficient dependent on the distance between the object point and the centre of projection.

\section{ACKNOWLEDGEMENTS}

The authors would like to thank: Dr. Francesco Fassi from Politecnico di Milano and Barbara de Cillis for supporting the diving activities during the underwater calibrations at sea; NiMAR (www.nimar.it) which supported this research by providing the photographic underwater equipment and for the useful insights about pressure housings manufacturing techniques; Sara Messina and Stefano Pucher from the Associazione Sportiva Dilettantistica Club Subacqueo Rane Nere Trento who supported the preliminary tests in the swimming pool in Trento; Mauro Saccone from LSIS, I\&M Team, Aix-Marseille Universite for supporting the underwater calibrations of the GOPRO Hero 4 in the testing pool of Polytech Luminy.

\section{REFERENCES}

Börlin, N. and Grussenmeyer, P., 2013. Bundle adjustment with and without damping. The Photogrammetric Record, Vol. 28(144), pp.396-415.

Brown, D.C, 1971. Close-range camera calibration. Photogramm. Eng, 37(8), pp.855-866.

Fraser, C.S., 1997. Digital camera self-calibration. ISPRS Journal of Photogrammetry and Remote sensing, 52(4), pp.149159.

Ghilani, C.D., 2017. Adjustment computations: spatial data analysis. John Wiley \& Sons.

Ivanoff, A., Cherney, P., 1960. Correcting lenses for underwater use. Journal of the SMPTE, 69(4), pp.264-266.

Jordt-Sedlazeck, A., Koch, R., 2012. Refractive calibration of underwater cameras. In: European conference on computer vision (pp. 846-859). Springer, Berlin, Heidelberg.

Kotowski, R., 1988. Phototriangulation in multi-media photogrammetry. In: The International Archives of the Photogrammetry, Remote Sensing and Spatial Information Sciences, Vol. 27, Kyoto.

Li, R., Li, H., Zou, W., Smith, R.G. and Curran, T.A., 1997. Quantitative photogrammetric analysis of digital underwater video imagery. IEEE Journal of Oceanic Engineering, 22(2), pp.364-375

Luhmann, T., Robson, S., Kyle, S. and Boehm, J., 2013. Closerange photogrammetry and $3 D$ imaging. Walter de Gruyter.

\section{MATLAB,}

https://it.mathworks.com/products/matlab.html?s_tid=hp_produ cts_matlab, (last access: April 2018)

Maas, H-G., 2015. On the accuracy potential in underwater/multimedia photogrammetry. Sensors 15, 1814018152; doi:10.3390/s150818140. 
Maas, H.-G, 1992. Digitale Photogrammetrie in der Dreidimensionalen Strömungsmesstechnik. Ph.D. Thesis, ETH Zürich, Zürich, Switzerland.

Menna, F.; Nocerino, E.; Remondino, F., 2018. Photogrammetric Modelling of Submerged Structures: Influence of Underwater Environment and Lens Ports on Three-Dimensional (3D) Measurements. In: Latest developments in reality-based $3 d$ surveying and modelling; Remondino, F., Georgopoulos, A., González-Aguilera, D., Agrafiotis, P., Eds.; MDPI: Basel, Switzerland, 2018; pp. 279-303.

Menna, F., Nocerino, E. and Remondino, F., 2017. Optical aberrations in underwater photogrammetry with flat and hemispherical dome ports. In: Videometrics, Range Imaging, and Applications XIV, SPIE Proc. Vol. 10332, p. 1033205.

Menna, F., Nocerino, E., Fassi, F. and Remondino, F., 2016. Geometric and optic characterization of a hemispherical dome port for underwater photogrammetry. Sensors, Vol. 16(1).

Rebikoff, D., 1968. The Rebikoff Pegasus underwater photographic system evolution, design criteria and typical applications In 1967. In: Underwater Photo-Optical Instrumentation Applications (pp. 91-100). International Society for Optics and Photonics.

Slater, D., 2014. Afocal viewport optics for underwater imaging. In SPIE Optical Engineering+ Applications. International Society for Optics and Photonics, pp. 91920P-91920P.

Telem, G. and Filin, S., 2010. Photogrammetric modeling of underwater environments. ISPRS Journal of Photogrammetry and Remote Sensing, 65(5), pp.433-444.

VDI/VDE, 2002. Guideline 2634 part 1, Optical 3D measuring systems - Imaging systems with point-by-point probing. VDI/VDE-Gesellschaft Mess- und Automatisierungstechnik. 